\title{
Формирование и исследование $p-i-n$-структур на основе двухфазного гидрогенизированного кремния со слоем германия в $i$-области
}

\author{
(C) Г.К. Кривякин ${ }^{1}$, В.А. Володин ${ }^{1,2}$, A.A. Шкляев ${ }^{1,2}$, V. Mortet ${ }^{3}$, J. More-Chevalier ${ }^{3}$, \\ P. Ashcheulov ${ }^{3}$, Z. Remes ${ }^{3}$, T.H. Stuchliková ${ }^{3}$ J. Stuchlik ${ }^{3}$ \\ ${ }^{1}$ Институт физики полупроводников им. А.В. Ржанова Сибирского отделения Российской академии наук, \\ 630090 Новосибирск, Россия \\ ${ }^{2}$ Новосибирский государственный университет, \\ 630090 Новосибирск, Россия \\ ${ }^{3}$ Institute of Physics ASCR, \\ v. v. i., Cukrovarnická 10/112, 16200 Praha 6, Czech Republic \\ E-mail: grisha992@gmail.com
}

(Получена 9 февраля 2017 г. Принята к печати 16 февраля 2017 г.)

Методом плазмохимического осаждения сформированы четыре пары $p-i-n$-структур на основе $p m-\mathrm{Si}: \mathrm{H}$ (полиморфного $\mathrm{Si}: \mathrm{H}$ ). Структуры в каждой паре выращивались на одной подложке так, что одна из них была без $\mathrm{Ge}$ в $i$-слое, а другая содержала $\mathrm{Ge}$, который осаждался слоем толщиной 10 нм методом вакуумного напыления. Пары различались между собой температурой подложки при осаждении Ge, которая была 300 , 350,400 и $450{ }^{\circ} \mathrm{C}$. Данные электронной микроскопии показали, что структуры, полученные при $300^{\circ} \mathrm{C}$, содержали нанокристаллы $\mathrm{Ge}(n c-\mathrm{Ge})$, центрами зарождения которых являлись нанокристаллические включения на поверхности $p m-\mathrm{Si}: \mathrm{H}$. Концентрация $n c-\mathrm{Ge}$ увеличивалась с возрастанием температуры. Исследование вольт-амперных характеристик показало, что наличие Ge в $i$-слое уменьшало плотность тока короткого замыкания в $p-i-n$-структурах, когда они использовались как солнечные элементы, тогда как наблюдалось увеличение тока под действием освещения при обратном смещении. Полученные результаты согласуются с известными данными для структур с кластерами $\mathrm{Ge}$ в $\mathrm{Si}$, согласно которым кластеры $\mathrm{Ge}$ увеличивают коэффициент поглощения света, но также увеличивают и скорость рекомбинации носителей.

DOI: $10.21883 /$ FTP.2017.10.45024.8547

\section{1. Введение}

Проблема повышения эффективности и стабильности недорогих солнечных элементов (СЭ) на основе гидрогенизированного аморфного кремния $(a-\mathrm{Si}: \mathrm{H})$ остается актуальной на протяжении десятков лет [1]. Интерес к СЭ, получаемым по низкотемпературной технологии, обусловлен в первую очередь возможностью использования нетугоплавких, в том числе гибких подложек, а также их относительно небольшой стоимостью.

Наиболее эффективным способом реализации СЭ на базе $a-\mathrm{Si}: \mathrm{H}$, если не принимать в рассмотрение дорогие многокаскадные решения, являются $p-i-n-$ и $n-i-p$-структуры. В последние годы усилия исследователей направлены на повышение эффективности и стабильности подобных структур путем встраивания в нелегированный $i$-слой нанокристаллических включений [2-4]. Известно, что присутствие в $a-\mathrm{Si}: \mathrm{H}$ $\sim(10-15) \%$ по объему нанокристаллического кремния (nc-Si) подавляет эффект Стеблера-Вронского [5], повышая стабильность СЭ [6-8]. Подобные пленки $a-\mathrm{Si}: \mathrm{H}$ с кристаллическими включениями являются двухфазными системами и в литературе обозначаются как pm-Si:H [1,9] (здесь pm означает polymorphous - полиморфный). Помимо этого использование включений из более узкозонного материала в некоторых случаях может привести к повышению коэффициента поглощения света, что должно повысить эффективность СЭ или дать возможность снизить их толщину без потери в эффективности. Подходящим материалом для таких включений является $\mathrm{Ge}$.

Ранее проводились исследования по внедрению квантовых точек $\mathrm{Ge}$ в $i$-слой кремниевых $p-i-n$-структур [10-12]; однако, как правило, в этих работах структуры были кристаллические, в то же время СЭ на базе $a-\mathrm{Si}: \mathrm{H}$ с нанокристаллическими включениями $\mathrm{Ge}$ $(n c-\mathrm{Ge})$ практически не исследованы. В качестве примера можно привести недавнюю работу [13], однако и в ней не все слои СЭ являлись аморфными, в частности в качестве нижнего $n$-слоя использовалась монокристаллическая подложка кремния.

В данной работе исследуется $p-i-n$-структура на базе $p m-\mathrm{Si}: \mathrm{H}$, в нелегированную область которой был встроен слой Ge. Пленки аморфного кремния с нанокристаллическими включениями выращивались с применением метода плазменно-химического осаждения (ПХО), в то время как Ge осаждался с применением метода вакуумного напыления. Встраивание $n c$-Ge в $i$-слой ранее использовалось в кристаллических структурах, где на поверхности проходил процесс самоорганизации Ge в наноостровки [10-12], однако его применимость для формирования $n c-\mathrm{Ge}$ на поверхности $p m-\mathrm{Si}: \mathrm{H}$ ранее не исследовалась. Таким образом, данная работа является первой попыткой формирования $p-i-n$-структур на базе $p m-\mathrm{Si}: \mathrm{H}$ с включениями $n c-\mathrm{Ge}$ на нетугоплавких прозрачных подложках. 


\section{2. Описание эксперимента}

Как уже отмечалось, для роста слоев $p m-\mathrm{Si}: \mathrm{H}$ использовался метод ПХО. Пленки осаждались из смеси моносилана $\left(\mathrm{SiH}_{4}\right)$ и водорода $\left(\mathrm{H}_{2}\right)$. Условия роста были оптимизированы таким образом, чтобы вместе с ростом $a$-Si:H происходило формирование включений $n c-\mathrm{Si}$. Температура подложки составляла $220^{\circ} \mathrm{C}$. Толщина слоев задавалась временем осаждения и контролировалась по данным эллипсометрии и электронной микроскопии.

Изготовление исследуемых образцов $p-i-n$-структур проходило в несколько этапов. На этапе 1 на нетугоплавкую стеклянную подложку (марка стекла JGS1) в качестве контакта наносилась титановая сетка с шагом 64 мкм по обеим координатам. Затем в качестве прозрачного электрода выращивался слой нанокристаллического алмаза, легированного бором (BDD - boron doped diamond). На этапе 2 методом ПХО осаждались $p$ и $i$-слои $p m-\mathrm{Si}: \mathrm{H}$ с толщинами 60 и 400 нм соответственно. Далее на этапе 3 образец вынимался из ростовой камеры ПХО и помещался в установку вакуумного напыления, в которой на половину его площади осаждался тонкий слой $\mathrm{Ge}$, толщиной $\sim 10$ нм. На этапе 4 образец помещался обратно в камеру ПХО, в которой на его поверхность осаждались $i$ - и $n^{+}$-слои $p m-\mathrm{Si}: \mathrm{H}$ с толщинами 140 и 80 нм соответственно. Осаждение проводилось при тех же условиях, что и во время осаждения предыдущих слоев $p m$-Si:H. На заключительном этапе 5 на поверхность структуры наносились алюминиевые контакты толщиной 200 нм и площадью $0.8 \times 0.8$ мм. Площадь всей структуры составляла $5 \times 10$ мм, таким образом, образец содержал несколько десятков контактных площадок. Схематическое изображение конечной структуры приведено на рис. 1 .

Необходимо отметить, что между этапами 2 и 3 , а также 3 и 4, когда образец выносился на воздух, поверхность $i$-слоя исследовалась с применением спектроскопии комбинационного рассеяния света (КРС) и сканирующей электронной микроскопии (СЭМ). После осаждения германия, непосредственно в ростовой камеpe, поверхность образцов исследовалась с применением атомно-силовой микроскопии (АСM). После изготовления структуры измерялись ее вольт-амперные характеристики (BAX), как темновые, так и световые при освещении галогеновой лампой. Плотность светового потока лампы была откалибрована таким образом, чтобы эталонный кремниевый фотоэлемент выдавал такой же ток при освещении лампой, как и при освещении в условиях AM1.5G. Спектры KРС регистрировались при комнатной температуре, для возбуждения использовалась линия излучения $\mathrm{Ar}^{+}$-лазера с длиной волны 514.5 нм, более подробно условия эксперимента описаны в работе [4].

Всего было изготовлено 4 образца, каждый из которых на этапе осаждения $\mathrm{Ge}$ нагревался до определенной температуры: $T=300,350,400$ и $450^{\circ} \mathrm{C}$. Как отмечалось выше, $\mathrm{Ge}$ осаждался только на половину площади (вторая половина была защищена экраном), однако при его осаждении образец нагревался целиком, что могло

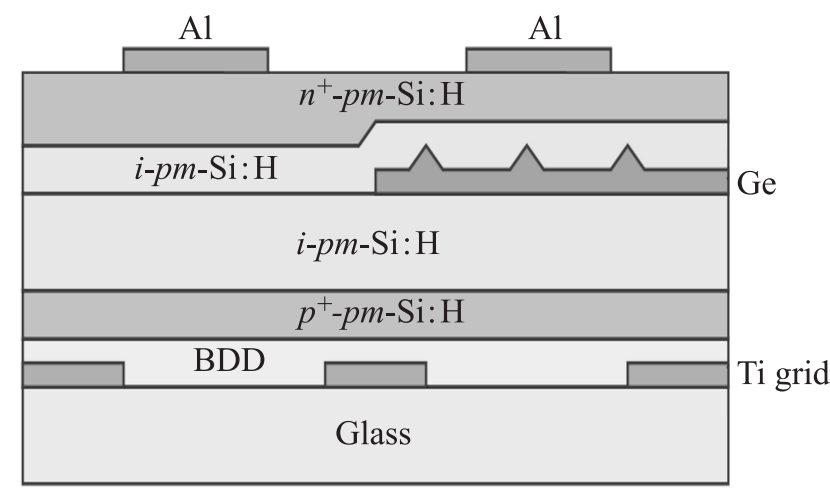

Рис. 1. Схематическое изображение исследуемых $p-i-n$ структур.

привести к структурным изменениям во всех слоях pm-Si:H. В результате для исследования было доступно 8 конфигураций $p-i-n$-структур: четыре со слоем $\mathrm{Ge}$ в $i$-области, осажденным при различных температурах, и четыре „спутника“ - без Ge, но отожженных при таких же температурах.

\section{3. Результаты и обсуждение}

Было проведено исследование спектров КРС $i$-слоя в области, не покрытой $\mathrm{Ge}$, для определения возможных структурных изменений пленок после их нагревания в процессе вакуумного напыления $\mathrm{Ge}$, в частности для контроля концентрации водорода. Анализ интегральных интенсивностей пиков $\mathrm{Si}-\mathrm{Si}-$ и $\mathrm{Si}-\mathrm{H}$-связей по методике, разработанной в [14], показал, что концентрация водорода в пленках уменьшалась с повышением их температуры в процессе МЛЭ. В неотожженной пленке интегральное содержание водорода составляло 24 ат\% ( 7 ат\% в состоянии $\mathrm{Si}-\mathrm{H}$ и 17 ат\% в состоянии $\mathrm{Si}-\mathrm{H}_{n}$ ). Отжиги в процессе вакуумного напыления $\mathrm{Ge}$ привели к уменьшению количества водорода в пленках. При температуре $350^{\circ} \mathrm{C}$ концентрация водорода составила 20 ат\% $\left(6\right.$ ат\% $\%$ Si-H и 14 ат\% $\left.-\mathrm{Si}-\mathrm{H}_{n}\right)$. При температуре $450^{\circ} \mathrm{C}$ концентрация водорода составила 13 ат\% $\left(4 \mathrm{aT} \%-\mathrm{Si}-\mathrm{H}\right.$ и 9 ат\% $\left.-\mathrm{Si}-\mathrm{H}_{n}\right)$. Таким образом, очевидно, что имел место процесс термической дегидрогенизации пленок $\mathrm{pm}-\mathrm{Si}: \mathrm{H}$.

На рис. 2, $a$ приведены спектры КРС $i$-области, не покрытой Ge. Отметим, что для удобства восприятия спектральный диапазон колебаний $\mathrm{Si}-\mathrm{H}$-связей $\left(2000-2100 \mathrm{~cm}^{-1}\right)$, который использовался для анализа концентрации водорода, не приведен на рис. 2. Характер спектров подтверждает наличие двухфазной системы $a-\mathrm{Si}: \mathrm{H}$ и $n c-\mathrm{Si}$. Видно, что с увеличением температуры растет интенсивность колебаний $\mathrm{Si}-\mathrm{Si}$-связей в кристаллической фазе, соответствующих рассеянию на оптических фононах, локализованных в нанокристаллах. Смещение положения пика от значения, характерного для объемного $c-\mathrm{Si}\left(520.6 \mathrm{~cm}^{-1}\right)$, подтверждает наличие в объеме пленок pm-Si:H нанокристаллической фазы. По его положению, согласно модели локализации фо- 

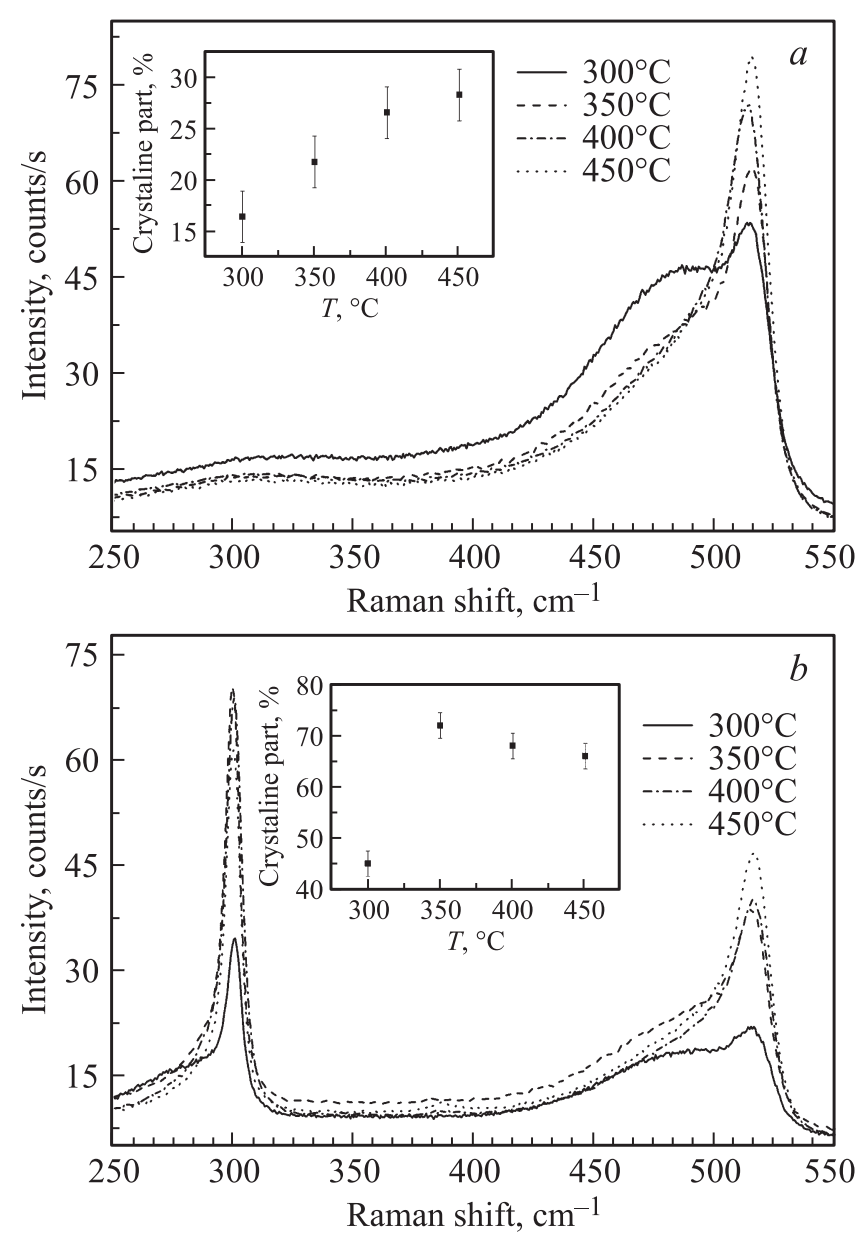

Рис. 2. Спектры комбинационного рассеяния света образцов: $a$ - область, не покрытая $\mathrm{Ge} ; b$ - область с осажденным $\mathrm{Ge}$. На вставках - доля кристаллической фазы в зависимости от температуры.

нонов [15-17], можно заключить, что средний размер нанокристаллов $n c-\mathrm{Si}$ составляет $\sim 3$ нм и заметно не меняется при увеличении температуры с 300 до $450^{\circ} \mathrm{C}$. В то же время при сравнении интенсивностей „аморфного“ и „кристаллического“ пиков видно, что с повышением температуры объемная доля нанокристаллической фазы увеличивается с 16 до 28\%. Доля нанокристаллической фазы определялась из соотношения интегральной интенсивности „нанокристаллического“ пика к сумме интегральных интенсивностей „аморфного“ и „нанокристаллического“ пика, как было предложено в работе [18]. Очевидно, что температуры, при которых происходил процесс осаждения $\mathrm{Ge}$, малы для появления кристаллических зародышей в аморфной фазе кремния, и естественно предположить, что увеличение объемной доли $n c-\mathrm{Si}$ обусловлено увеличением размеров уже введенных на стадии ПХО нанокристаллических зародышей, однако анализ КРС показывает, что размер $n c-\mathrm{Si}$ практически не меняется. Поэтому единственным объяснением роста нанокристаллической фазы может быть разрастание мелких $n c$-Si до размеров $\sim 3$ нм. Как известно из работ [15-17], пик $n c-\mathrm{Si}$ не является симмет- ричным, он имеет плечо со стороны меньших волновых чисел, однако его асимметричность может быть связана и с дисперсией $n c$-Si по размеру. При анализе спектров вклад от $n c-\mathrm{Si}$ аппроксимировался двумя пиками Гаусса (для удобства восприятия, чтобы не загромождать рисунок, результаты аппроксимации не приведены в данной работе), и было видно, что при переходе от 300 до $350^{\circ} \mathrm{C}$ низкочастотное плечо пика уменьшается, что с большой вероятностью является следствием разрастания мелких $n c$-Si. Тем не менее существенного уменьшения низкочастотного плеча при переходе к более высоким температурам не наблюдалось. Вопрос, почему рост происходит только до значений $\sim 3 \mathrm{HM}$, пока остается открытым. Возможно, так проявляется влияние механических напряжений, возникающих вследствие того, что плотность кристаллического кремния на $~ 3 \%$ больше плотности аморфного кремния [19].

Немного другое поведение характерно для спектров КРС $i$-слоя в областях, покрытых $\mathrm{Ge}$, приведенных на рис. $2, b$. Видно, что при напылении Ge часть его осаждается на поверхность в аморфной фазе $(a-\mathrm{Ge})$, а часть - в кристаллической $(c-\mathrm{Ge})$, причем при повышении температуры с 300 до $350^{\circ} \mathrm{C}$ доля $c$-Ge увеличивалась с 45 до $\sim 70 \%$, а при более высоких температурах роста (в пределах ошибки) оставалась практически прежней, как показано на вставке к рис. $2, b$.

Положение „кристаллического“ пика рассеяния на колебаниях $\mathrm{Ge}-\mathrm{Ge}-$ связей во всех случаях находится в диапазоне 299-300 $\mathrm{cm}^{-1}$, в то же время его положение для объемного $c$-Ge составляет $301.5 \mathrm{~cm}^{-1}$. По смещению пика из модели локализации фононов можно заключить, что размер $n c$-Ge лежит в диапазоне 5-6 нм. Отметим, что Ge наносился на поверхность $p m-\mathrm{Si}: \mathrm{H}$ методом вакуумного напыления и, хотя данная поверхность по большей части аморфная, в тонкой пленке Ge могут присутствовать механические напряжения сжатия, которые также вносят вклад в сдвиг положения кристаллического пика. Сжатие приводит к смещению частот фононов в область бо́льших частот. Исходя из этого сложно найти точный размер $n c-\mathrm{Ge}$, но можно заключить, что средний размер нанокристаллов не превышает 6 нм.

В работе [20] уже исследовался вопрос о напылении Ge на поверхность $a$-Si:H методом МЛЭ. Было показано, что при температуре $300^{\circ} \mathrm{C}$ осажденный $\mathrm{Ge}$ находится в аморфной фазе, а нанокристаллическая фаза появляется при температуре роста $350^{\circ} \mathrm{C}$. Однако в нашем случае уже при $300^{\circ} \mathrm{C}$ наблюдается $n c-\mathrm{Ge}$. Можно предположить, что нанокристаллы $n c$-Si на поверхности $p m-\mathrm{Si}$ выступают в роли зародышей для $n c-\mathrm{Ge}$, т.е. можно сказать что имел место процесс „локальной эпитаксии“.

На рис. 3 приведены СЭМ-изображения поверхности $i$-слоя каждой конфигурации $p-i-n$-структуры. Изображения областей, не покрытых $\mathrm{Ge}$, показывают, что выращенные пленки pm-Si:H, по-видимому, имеют неоднородную столбчатую структуру, что характерно для двухфазных систем на основе кремния при их росте при низкой температуре. 

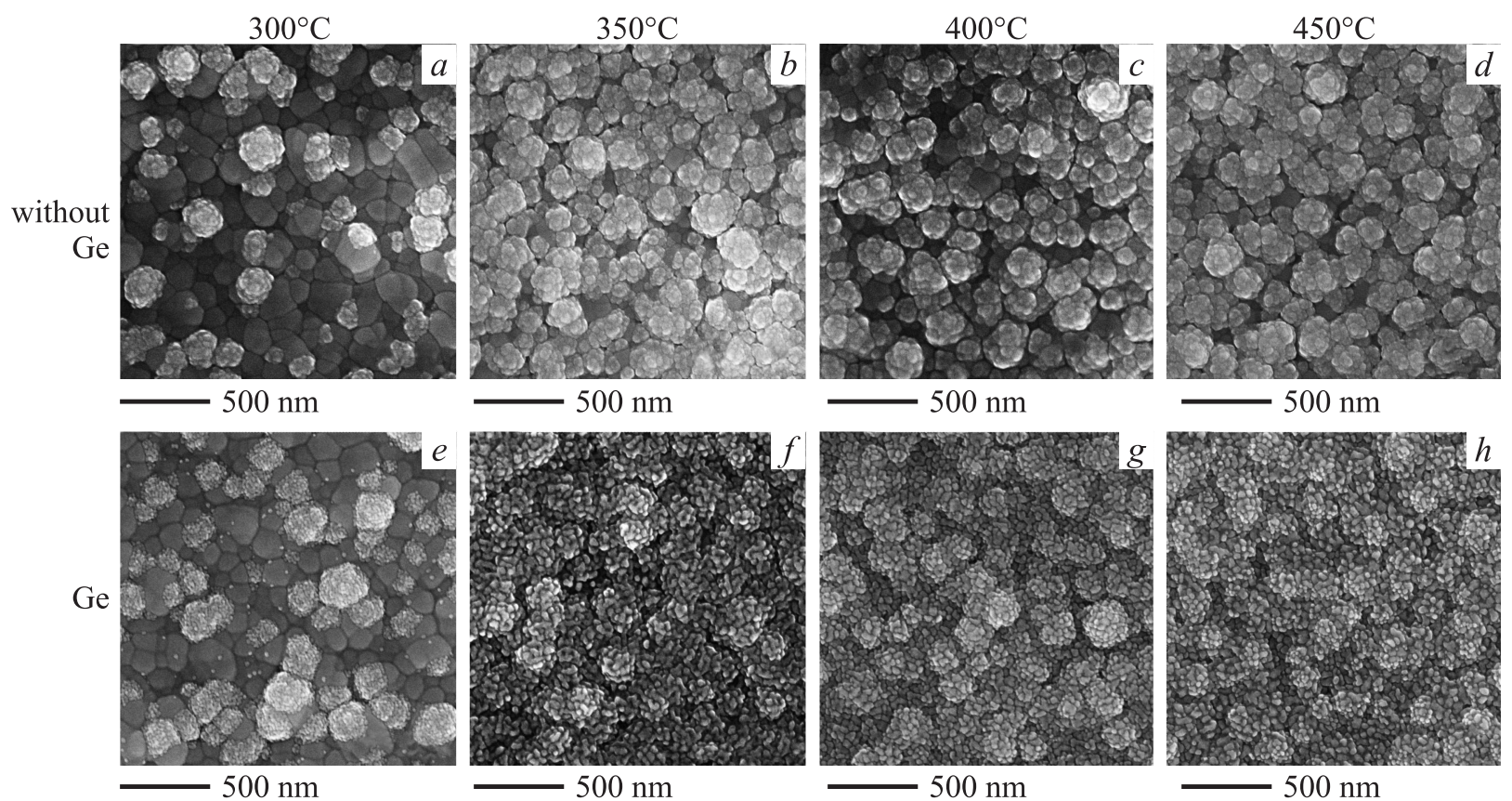

Рис. 3. СЭМ-изображения образцов: $a, b, c, d$ - области, не покрытые $\mathrm{Ge} ; e, f, g, h$ - области с осажденным $\mathrm{Ge}$.

Рассмотрим изображения поверхности без Ge. В случае $300^{\circ} \mathrm{C}$ (рис. 3, $a$ ) в рельефе поверхности можно выделить участки двух видов: гладкий (темный на изображении), и гранулоподобный (более светлый), с размерами гранул в диапазоне $100-250$ нм. Вместе с тем в случае $350^{\circ} \mathrm{C}$ (рис. $3, b$ ) видно, что почти вся поверхность обладает гранулоподобным рельефом и в дальнейшем при повышении температуры ее морфология не меняется (рис. 3, $c$ и $d$ ).

Схожую морфологию показывают те же исходные поверхности, но уже покрытые Ge. В случае $300^{\circ} \mathrm{C}$ (рис. $3, e$ ) поверхности с осажденным Ge также содержат участки двух видов: участки скопления мелких кластеров размером $\sim 25$ нм и гладкие участки с крайне редким расположением мелких кластеров на них. При использовании $T=350,400$ и $450^{\circ} \mathrm{C}$ уже вся поверхность покрыта мелкими кластерами. Качественные изменения в рельефе для поверхностей, покрытых Ge, хорошо коррелируют с изменениями рельефа поверхностей без Ge, а также со спектрами КРС. Как уже отмечалось, при $300^{\circ} \mathrm{C}$ объемная доля кристаллического $\mathrm{Ge}$ составляет $45 \%$, а при температурах $350^{\circ} \mathrm{C}$ и выше она практически не меняется, и имеет постоянное значение 70\%.

Анализ СЭМ-изображений позволяет сделать вывод, что $\mathrm{Ge}$ эффективно собирается в кластеры там, где поверхность pm-Si:H имеет гранулоподобный рельеф. Такой рельеф, как показано на рис. 4, а, образуется при использовании низких температур, включая $400^{\circ} \mathrm{C}$. Можно предположить, что в результате кратковременной выдержки на воздухе перед загрузкой образца в камеру вакуумного напыления поверхность pm-Si:H могла быть покрыта сверхтонким слоем оксида. Известно, что рост Ge на оксидированной поверхности происходит посредством образования плотного массива кластеров $\mathrm{Ge}$, которые при толщине слоя осажденного Ge 10 нм могут касаться друг друга (рис. 4,a) [21]. При температуpax $>400^{\circ} \mathrm{C}$ осаждение $\mathrm{Ge}$ сопровождается испарением молекул $\mathrm{SiO}$ и $\mathrm{GeO}$ [22]. Это приводит к частичному удалению оксида с поверхности образца. В результате на поверхности образуются кластеры с большей концентрацией и меньшими размерами. В целом поверхность становится более плоской, как показано на рис. $4, b$.

Основной целью работы было определение влияния встроенного $i$-слоя с $n c$-Ge на эффективность фотоэлектрического преобразования СЭ, изготовленных на базе $\mathrm{pm}-\mathrm{Si}: \mathrm{H}$. Для каждого образца были измерены как темновые, так и световые ВАХ, которые для структур, нагретых до $300^{\circ} \mathrm{C}$ во время напыления $\mathrm{Ge}$, приведены на рис. 5. Световые ВАХ измерялись при освещении галогеновой лампой. В таблице приведена краткая сводка полученных результатов. Вопреки ожиданиям, наличие $n c$-Ge в активном слое $\mathrm{CЭ}$ не привнесло положительного эффекта. Напряжение холостого хода $\left(U_{o c}\right)$ во всех случаях было равно 0.2 В и лишь для образца, нагретого до $350^{\circ} \mathrm{C}$, без $n c$-Ge достигло $0.3 \mathrm{~B}$. Если говорить о величине плотности тока короткого замыкания $J_{s c}$, то тут наблюдается даже отрицательная тенденция. Наличие $n c-\mathrm{Ge}$ во всех случаях уменьшало значение $J_{s c}$. Это уменьшение было больше для структур, процесс МЛЭ которых проводился при более высоких температурах, и в случаях $300,350,400$ и $450^{\circ} \mathrm{C}$ оно составляло 25,51 , 20 и $42 \%$ соответственно.

Наличие слоя $\mathrm{Ge}$ толщиной 10 нм в $i$-слое должно приводить к увеличению поглощения света, особенно в спектральной области ближнего инфракрасного (ИК) диапазона, поэтому ухудшение СЭ по такому параметру, как $J_{s c}$, очевидно, связано с тем, что $n c$-Ge являлись дополнительными центрами рекомбинации. Рекомбинация 
Плотности токов при прямом и обратном смещении, плотность тока короткого замыкания $\left(J_{s c}\right)$ и напряжение холостого хода $\left(U_{o c}\right)$ для исследованных $p-i-n$-структур

\begin{tabular}{|c|c|c|c|c|c|c|c|}
\hline & & \multicolumn{2}{|c|}{ Темновой ток } & \multicolumn{4}{|c|}{ Освещение } \\
\hline \multicolumn{2}{|c|}{ Образец } & $J(U=2.5 \mathrm{~B})$, & $J(U=-2.5, \mathrm{~B})$ & $J(U=2.5 \mathrm{~B})$, & $J(U=-2.5 \mathrm{~B})$, & $J_{s c}$ & $U_{o c}$, \\
\hline $300^{\circ} \mathrm{C}$ & $\begin{array}{c}\text { без } \mathrm{Ge} \\
\mathrm{c} \mathrm{Ge}\end{array}$ & $\begin{array}{l}1.22 \\
1.83\end{array}$ & $\begin{array}{l}0.07 \\
0.15\end{array}$ & $\begin{array}{l}1.30 \\
1.83\end{array}$ & $\begin{array}{l}0.08 \\
0.16\end{array}$ & $\begin{array}{l}3.66 \\
2.74\end{array}$ & $\begin{array}{l}0.2 \\
0.2\end{array}$ \\
\hline $350^{\circ} \mathrm{C}$ & $\begin{array}{c}\text { без } \mathrm{Ge} \\
\mathrm{c} \mathrm{Ge}\end{array}$ & $\begin{array}{l}0.46 \\
0.86\end{array}$ & $\begin{array}{l}0.02 \\
0.10\end{array}$ & $\begin{array}{l}0.55 \\
0.93\end{array}$ & $\begin{array}{l}0.03 \\
0.12\end{array}$ & $\begin{array}{l}4.36 \\
2.13\end{array}$ & $\begin{array}{l}0.3 \\
0.2\end{array}$ \\
\hline $400^{\circ} \mathrm{C}$ & $\begin{array}{c}\text { без } \mathrm{Ge} \\
\mathrm{c} \mathrm{Ge}\end{array}$ & $\begin{array}{l}0.45 \\
1.46\end{array}$ & $\begin{array}{l}0.01 \\
0.10\end{array}$ & $\begin{array}{l}0.51 \\
1.52\end{array}$ & $\begin{array}{l}0.02 \\
0.11\end{array}$ & $\begin{array}{l}2.53 \\
2.02\end{array}$ & $\begin{array}{l}0.2 \\
0.2\end{array}$ \\
\hline $450^{\circ} \mathrm{C}$ & $\begin{array}{c}\text { без } \mathrm{Ge} \\
\mathrm{c} \mathrm{Ge}\end{array}$ & $\begin{array}{l}0.80 \\
0.44\end{array}$ & $\begin{array}{l}0.03 \\
0.02\end{array}$ & $\begin{array}{l}0.89 \\
0.54\end{array}$ & $\begin{array}{l}0.04 \\
0.03\end{array}$ & $\begin{array}{l}3.76 \\
2.32\end{array}$ & $\begin{array}{l}0.2 \\
0.2\end{array}$ \\
\hline
\end{tabular}

могла происходить как через электронные состояния на границах $n c-\mathrm{Ge} / a-\mathrm{Ge}$ и $n c-\mathrm{Ge} / a-\mathrm{Si}: \mathrm{H}$, так и через уровни в $n c$-Ge. Недавно было показано, что существует и объективная причина для уменьшения $U_{o c}$, которая обусловлена меньшей шириной запрещенной зоны Ge по сравнению с Si [23]. При этом наличие кластеров Ge в $\mathrm{Si}$ увеличивает скорость рекомбинации носителей заряда [24].

Известно, что электронные переходы внутри $n c-\mathrm{Ge}$ могут быть прямыми, что представляет интерес для их

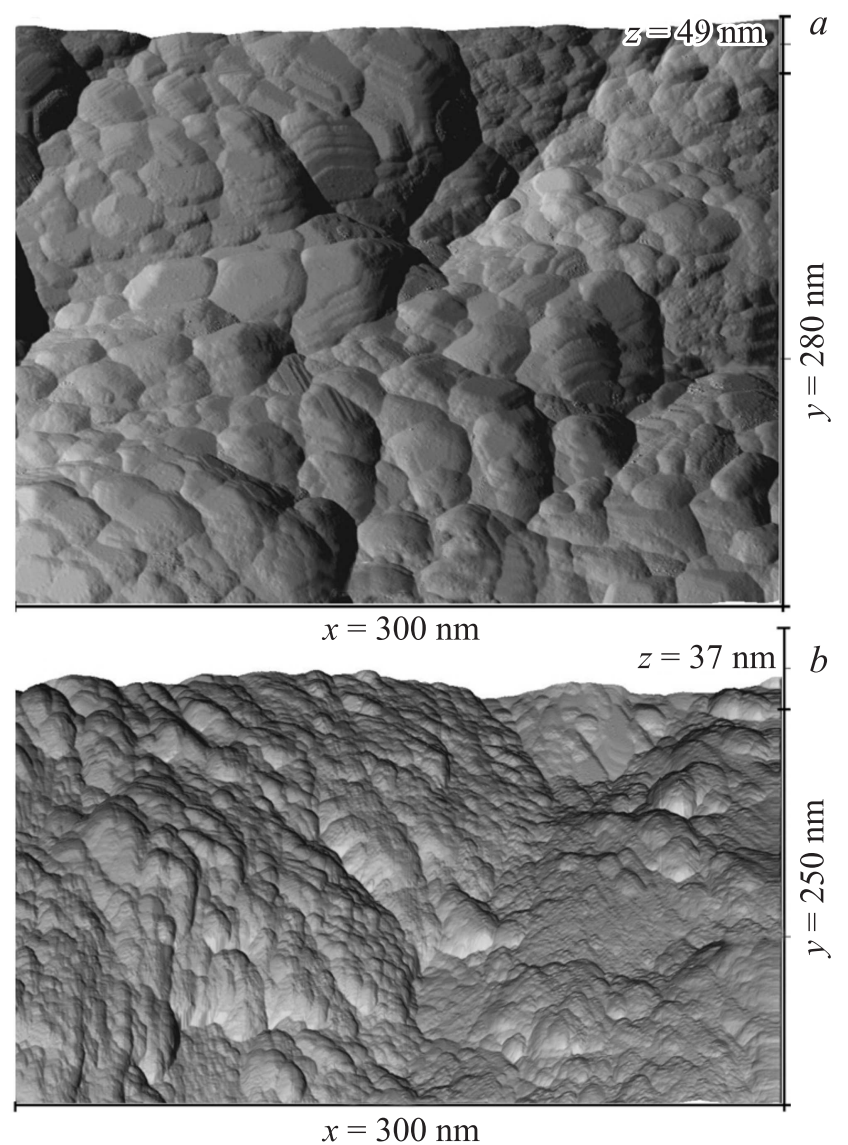

Рис. 4. СТМ-изображения образцов после осаждения 10 нм Ge при $400(a)$ и $450^{\circ} \mathrm{C}(b)$.

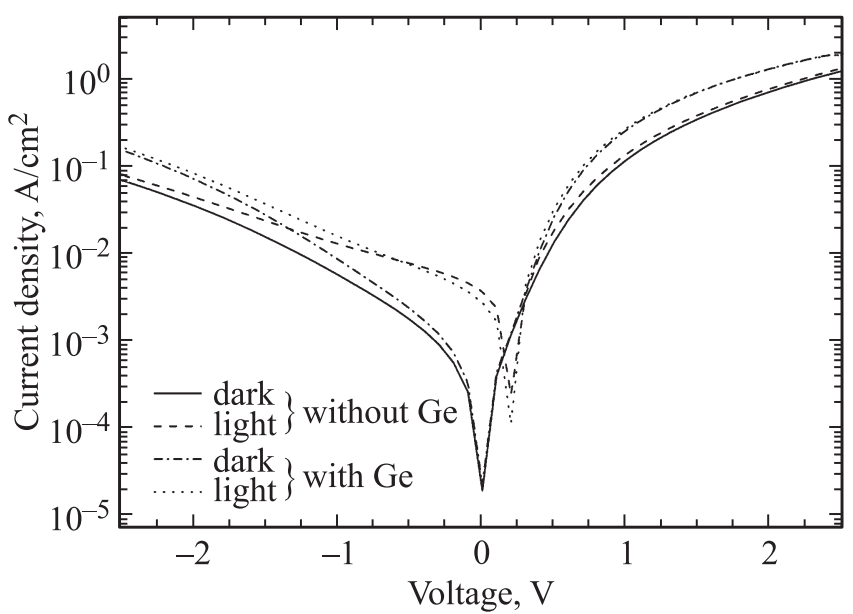

Рис. 5. Световые и темновые ВАХ обеих областей $p-i-n$ диодной структуры (c Ge и без него), полученной при $300^{\circ} \mathrm{C}$.

применения в светоизлучающих устройствах. Во всех структурах была исследована электролюминесценция при прямом смещении при комнатной температуре, однако сигнал был слабый, что говорит о низком квантовом выходе. Следует отметить, что негативный вклад в BAX наших образцов могли вносить остатки тонкого слоя ( 0.5 нм) естественного окисла, который образовывался в структурах между стадиями их изготовления.

Положительным результатом является то, что в структурах с включением Ge наблюдались более сильные токи при обратном смещении при освещении солнечным эталоном. По всей вилимости это является следствием повышения поглощения света видимого диапазона и увеличении генерации носителей заряда в $n c-\mathrm{Ge}$ с атомами кислорода на границах [25]. Возможно, при оптимизации слоев можно достичь хорошей фоточувствительности данных структур и в ближнем ИК-диапазоне. Это актуально для создания фотодетекторов, работающих без дополнительной подсветки при естественном фоне засветки ночного неба [26]. 


\section{4. Заключение}

Изготовлены и исследованы макеты СЭ, представляющие собой $p-i-n$-структуры на базе $p m-\mathrm{Si}: \mathrm{H}$ c включениями $n c$-Ge в $i$-слое. Произведено сравнение их характеристик с аналогичными структурами без $n c$-Ge. Результаты показали, что наличие $\mathrm{Ge}$ в активной области не улучшает качества СЭ, вероятно, по причине того, что $n c$-Ge вносят дополнительные центры рекомбинации. В то же время наличие центров рекомбинации может быть использовано в светоизлучающих диодах и фотодетекторах для видимого и ближнего ИК диапазонов, однако это требует отдельных исследований.

Работа поддержана программой KONNECT 007 of the ASCR, v.v.i., программой 13-31783S of Czech Science Foundation and the J.E. Purkyně e fellowship awarded to V. Mortet by the ASCR, v.v.i. В части исследования оптических свойств работа выполнена по государственному заданию - Программа фундаментальных исследований CO PAH № II.9.4.

Рост слоев $\mathrm{Ge}$ и исследование морфологии поверхности проводились при финансовой поддержке РНФ (грант № 14-22-00143).

\section{Список литературы}

[1] В.П. Афанасьев, Е.И. Теруков, А.А. Шерченков. Тонкопленочные солнечные элементы на основе кремния, 2-е изд. (СПб., Изд-во СПбГЭТУ „ЛЭТИ“, 2011).

[2] N.G. Galkin, K.N. Galkin, I.M. Chernev, R. Fajgar, T.H. Stuchlikova, Z. Remes, J. Stuchlik. Phys. Status Solidi C, 10, 1712 (2013).

[3] N.G. Galkin, K.N. Galkin, I.M. Chernev, R. Fajgar, T.H. Stuchlikova, J. Stuchlik, Z. Remes. JJAP Conf. Proc., 3, 011104 (2015).

[4] Г.К. Кривякин, В.А. Володин, С.А. Кочубей, Г.Н. Камаев, A. Purkrt, Z. Remes, R. Fajgar, T.H. Stuchliková, J. Stuchlik. ФТП, 50, 952 (2016).

[5] D.L. Staebler, C.R. Wronski. Appl. Phys. Lett., 34, 292 (1997).

[6] A.V. Emelyanov, A.G. Kazanskii, P.A. Forsh, D.M. Zhigunov, M.V. Khenkin, N.N. Petrova, A.V. Kukin, E.I. Terukov, P.K. Kashkarov. J. Nanoelectron. Optoelectron., 10, 649 (2015).

[7] C.R. Wronski, J.M. Pearce, J. Deng, V. Vlahos, R.W. Collins. Thin Sol. Films, 451-452, 470 (2004).

[8] А.Г. Казанский, Е.И. Теруков, П.А. Форш, J.P. Kleider. ФТП, 44, 513 (2010).

[9] R. Butté, S. Vignoli, M. Meaudre, R. Meaudre, O. Marty, L. Saviot, P. Roca i Cabarrocas. J. Non-Cryst. Solids, 266, 263 (2000).

[10] A.I. Yakimov, A.V. Dvurechenskii, Yu.Yu. Proskuryakov, A.I. Nikiforov, O.P. Pchelyakov, S.A. Teys, A.K. Gutakovskii. Appl. Phys. Lett., 75, 1413 (1999).

[11] A. Alguno, N. Usami, T. Ujihara, K. Fujiwara, G. Sazaki, K. Nakajima. Appl. Phys. Lett., 84, 2802 (2004).

[12] Z. Liu, T. Zhou, L. Li, Y. Zuo, C. He, C. Li, C. Xue, B. Cheng, Q. Wang. Appl. Phys. Lett., 103, 082101 (2013).

[13] C. Li, J. Ni, X. Sun, X. Wang, Z. Li, H. Cai, J. Li, J. Zhang. J. Phys. D: Appl. Phys., 50, 045108 (2017)
[14] V.A. Volodin, D.I. Koshelev. J. Raman Spectrosc., 44, 1760 (2013).

[15] R. Tsu, J. Gonzalez-Hernandes, S.S. Chao, S.C. Lee, K. Tanaka. Appl. Phys. Lett., 40, 534 (1982).

[16] V. Pailard, P. Puech. J. Appl. Phys., 86, 1921 (1999).

[17] В.А. Володин, В.А. Сачков. ЖЭТФ, 143, 100 (2013).

[18] E. Bustarret, M.A. Hachicha, M. Brunel. Appl. Phys. Lett., 52, 1675 (1988).

[19] M.D. Efremov, V.V. Bolotov, V.A. Volodin, L.I. Fedina, E.A. Lipatnikov. J. Phys.: Condens. Matter, 8, 273 (1996).

[20] А.В. Двуреченский, В.А. Володин, Г.К. Кривякин, А.А. Шкляев, С.А. Кочубей, И.Г. Неизвестный, J. Stuchlik. Автометрия, 52, 97 (2016).

[21] A.A. Shklyaev, K.N. Romanyuk, S.S. Kosolobov. Surf. Sci., 625, 50 (2014).

[22] A.A. Shklyaev, M. Shibata, M. Ichikawa. Phys. Rev. B, 62 , 1540 (2000).

[23] T. Tayagaki, Y. Hoshi, N. Usami. Sci. Rep., 3, 2703 (2013).

[24] А.Н. Яблонский, Н.А. Байдакова, А.В. Новиков, Д.Н. Лобанов, М.В. Шалеев. ФТП, 49, 1458 (2015).

[25] S. Cosentino, E.G. Barbagiovanni, I. Crupi, M. Miritello, G. Nicotra, C. Spinella, D. Pacifici, S. Mirabella, A. Terrasi. Sol. Energy Mater. Sol. Cells, 135, 22 (2015).

[26] М.С. Смагин. Датчики и системы, 5, 43 (2016).

Редактор Л.В. Шаронова

\section{Formation and study of $p-i-n$-structures based on two-phase hydrogenated silicon with germanium inclusions in the $i$-layer}

\author{
G.K. Krivyakin ${ }^{1}$, V.A. Volodin ${ }^{1,2}$, A.A. Shklyaev ${ }^{1,2}$, \\ V. Mortet ${ }^{3}$, J. More-Chevalier ${ }^{3}$, P. Ashcheulov ${ }^{3}$, \\ Z. Remes ${ }^{3}$, T.H. Stuchliková ${ }^{3}$, J. Stuchlik ${ }^{3}$ \\ ${ }^{1}$ Institute of Semiconductor Physics, \\ Russian Academy of Sciences, \\ 630090 Novosibirsk, Russia \\ ${ }^{2}$ Novosibirsk State University, \\ 630090 Novosibirsk, Russia \\ ${ }^{3}$ Institute of Physics ASCR, \\ v.v.i., Cukrovarnická 10/112, \\ 16200 Praha 6, Czech Republic
}

\begin{abstract}
Plasma enhanced chemical vapor deposition was used to fabricate four pairs of $p-i-n$-structures based on $p m-\mathrm{Si}: \mathrm{H}$. The structures in each of the pairs were grown on the same substrate so that one of them did not contain Ge in the $i$-layer, whereas the other contained $\mathrm{Ge}$, deposited as a layer of $10 \mathrm{~nm}$ thickness by molecular-beam epitaxy. The pairs differed from each other by the substrate temperature during the Ge deposition, which were $300,350,400$ and $450^{\circ} \mathrm{C}$. The electron microscopy data showed that the structures prepared at $300^{\circ} \mathrm{C}$ contained Ge nanocrystals ( $n c-\mathrm{Ge})$ nucleated due to nanocrystalline inclusions in $\mathrm{pm}$-Si:H. The $n c-G e$ concentration increased with the temperature. The study of current-voltage characteristics revealed that the presence of $\mathrm{Ge}$ in $i$-layers decreased the short circuit current density of the $p-i-n$-structures when they were used as solar cells, whereas they initiated a current increase at a reverse bias under irradiation. The obtained results agree to the known data for the structures with $\mathrm{Ge}$ clusters in $\mathrm{Si}$, according to which the clusters increase the light absorption coefficient, but they also increase the carriers recombination rate.
\end{abstract}

